\title{
Purposeful Review to Identify Risk Factors, Epidemiology, Clinical Features, Treatment and Prevention of Chronic Kidney Disease of Unknown Etiology
}

This article was published in the following Dove Press journal:

International Journal of Nephrology and Renovascular Disease

\section{Daba Abdissa (iD}

Department of Biomedical Sciences, College of Medical Science, Institute of Health Science, Jimma University, Jimma, Ethiopia

Correspondence: Daba Abdissa Jimma University, Jimma, Ethiopia Email dhaabaa4@gmail.com

\begin{abstract}
The global burden of chronic kidney disease (CKD) has risen, and chronic kidney disease of unknown etiology $(\mathrm{CKDu})$ contributes considerably to the national burden of CKD. It is characterized by irreversible, slowly advancing disease, and symptoms often appear in the late stages of the disease. It is a serious, novel cause of kidney failure and leads to premature deaths. Many hypotheses have emerged; however, the etiology of CKDu continues to be elusive and debatable and it is claimed that the etiology is multifactorial, encompassing environmental, genetic, occupational, and social factors. The dominant histopathological feature is chronic tubulointerstitial nephritis. It predominantly affects individuals with low socio-economic status, of working age, largely without chronic comorbidities, who perform strenuous labor in extreme conditions in various tropical areas of the world. It is often fatal due to fast progression and limited access to dialysis or transplant options in the involved geographic areas. Early recognition and appropriate interventions at the earliest possible stage are imperative for decreasing its associated morbidity and mortality. In this review, I tried to summarize available evidence on the risk factors, epidemiology, clinical features, treatment, and prevention of CKDu. The literature search for this review was conducted comprehensively by using different electronic databases and by using appropriate search terms.
\end{abstract}

Keywords: chronic kidney disease of unknown etiology, review, risk factors

\section{Introduction}

Chronic kidney disease (CKD) is a global health problem. According to projections from the global health observatory, it is currently one of the rapidly growing causes of mortality worldwide. ${ }^{1}$ Chronic kidney disease disproportionately affects lowincome and middle-income countries with a prevalence of $15 \%$ higher than that of high-income countries. ${ }^{2}$ The primary cause of CKD varies by setting, with hypertension and diabetes being the most common causes, ${ }^{3}$ but chronic kidney disease of unknown cause $(\mathrm{CKDu})$ is an emerging health problem predominantly in low and middle income countries. 4

Chronic kidney disease of unknown etiology has no association with the known risk factors such as hypertension, diabetes or chronic glomerulonephritis. It has no common global definition and the term CKDu was first used in El Salvador in the early 2000 s to show a disease frequently affecting agricultural societies, ${ }^{5}$ and as the 
etiology was not clear, the term "chronic kidney disease of unknown etiology" has been used in the literature since 2000s. Other terms used include "Mesoamerican nephropathy", "CKD of nontraditional cause", "kidney disease of unknown cause in agricultural laborers", etc. It is typically characterized by an insidious development of chronic kidney disease (CKD) with a decreased estimated glomerular filtration rate (eGFR) without common risk factors of $\mathrm{CKD}^{4}{ }^{4}$ It is of great concern and poses a great risk to the health of communities. Communities living around hot, coastal/subcostal, low-altitude, tropical/subtropical geographical areas are commonly affected. ${ }^{6}$ It usually affects low income, rural and middle-aged men working in agriculture or other fieldworkers requiring extenuating work. ${ }^{4}$

In low-income countries, early detection and prevention of CKDu is crucial in order to decrease disease progression, since there is only limited access to health care to manage late complications. Moreover, disease awareness and surveillance systems are poor among both the health-care authorities and general public, thus the real burden of disease is unknown. ${ }^{7}$ The consequences are disastrous for patients and their families, due to loss of productivity and inability to support their families because the disease often affects working-age groups. There is relatively deficient, scattered and limited summarized evidence regarding $\mathrm{CKDu}$ and it is usually an overlooked condition in developing countries. Hence, I summarized available evidence on diagnosis, screening methods, risk factors, epidemiology, prevention and treatment strategies of CKDu which will provide input for further efforts to address the epidemic.

\section{Methods}

For this review article I searched PubMed, Science Direct, Web of Science and Google scholar and other databases to get as many relevant articles as possible. Articles were considered relevant and included in the review if they: i) evaluated $\mathrm{CKDu}$ including its epidemiology, potential risk factors, treatment and ways of prevention, ii) were published in English, iii) were published from 2010 until November 2020. I excluded opinion papers and articles with insufficient data on methods and those that lacked data in the results section. I screened the identified articles using titles and abstracts before doing a full article review.

Search terms included a combination of appropriate search terms for chronic kidney disease of unknown etiology including its related synonyms like "Mesoamerican nephropathy" "CKDu", "agricultural nephropathy", "chronic kidney disease of nontraditional cause", "potential risk factors", "epidemiology", "treatment" and "prevention ways". Moreover, the searches were supplemented by reviewing the bibliography of the selected studies to identify relevant additional studies.

\section{Diagnosis and Screening}

Diagnosis is considered in patients with decreased glomerular filtration rate without typical risk factors of CKD and who have experienced long times of physically demanding agricultural work in hot climate with the risk of becoming dehydrated. ${ }^{8}$ It is a diagnosis of exclusion, made when a patient fulfills the Kidney Disease Improving Global Outcomes CKD criteria without evidence of a recognized cause such as diabetes, hypertension, genetic disease, or glomerulonephritis. ${ }^{9}$ It is defined by an eGFR of $<60 \mathrm{~mL} /$ min per $1.73 \mathrm{~m}^{2}$ in the absence of traditional risk factors, heavy proteinuria, and structural renal disease, based on two measures of serum creatinine three months apart. ${ }^{10}$

It is characterized by slowly progressive, irreversible disease and there is either significant or at least $50 \%$ damage at the time of detection due to few or no symptoms being present until the disease is fairly advanced. ${ }^{11,12}$ The nephropathy progresses silently to end-stage renal disease (ESRD) leading to premature death among thousands of workers. ${ }^{13}$ Studies suggest that some workers at risk for $\mathrm{CKDu}$ are experiencing episodes of clinically apparent acute interstitial nephritis with renal biopsies demonstrating tubulointerstitial inflammatory infiltrates with varying degrees of underlying fibrosis. ${ }^{14,15}$ Progression from initial onset to end-stage kidney disease can be rapid in some patients especially if they do not get treatment in time. ${ }^{16,17}$ Hence, prevention, early screening of etiological factors, and early diagnosis are key to initiate timely treatment and slow down the progression to end-stage kidney disease. ${ }^{4}$

The main biomarkers for identification and screening of $\mathrm{CKDu}$ include serum creatinine, eGFR and dipstick proteinuria measurements, in order to exclude known etiologies of CKD. ${ }^{17}$ However, dipstick proteinuria has limited sensitivity and has high probability for human error. Creatinine measurement is favorable over dipstick proteinuria owing to its apparent accuracy and cost efficiency. Creatinine and albumin to creatinine ratio (ACR), in a complementary manner, can overcome shortcomings of dipstick proteinuria. In addition, use of ACR may also increase the ability to clinically discriminate CKDu from other glomerular nephropathies. ${ }^{18}$ 
Biomarkers that are tubular specific are excreted at an initial stage of CKDu and can be specific and sensitive for screening and early diagnosis of CKDu. ${ }^{19}$ Biomarkers that are sensitive to tubular injury, like urinary neutrophil gelatinase-associated lipocalin (NGAL)-to-creatinine ratio, are more suitable for early diagnosis of $\mathrm{CKDu}$ than $\mathrm{ACR} .{ }^{20}$ Similarly, urinary kidney injury molecule-1(KIM-1) can serve as an early marker of $\mathrm{CKDu}$. According to Ratnayake et al, serum cystatin $\mathrm{C}$ is the most accurate functional marker in detecting $\mathrm{CKDu}$ in endemic regions. ${ }^{21}$ Those tests represent more sensitive screening tools, although their cost prevents widespread use. ${ }^{22}$

\section{Epidemiology}

The prevalence of CKDu differs greatly across the world, as does its detection; and treatment varies. It is highly prevalent among low-income rural societies in the tropics. Geographic hotspots of CKDu include El Salvador, Bulgaria, Guatemala, Mexico, Nicaragua, Croatia, Egypt, Serbia, India, and Sri Lanka. ${ }^{23-25}$ In Central America it is a leading cause of hospitalization and death, mainly among young, male sugarcane workers. ${ }^{14,26}$ The true burden of this disease has not been well documented, because of the limitations of surveillance and the lack of a consensus on diagnostic criteria or case definition. ${ }^{27,28}$ Less is generally known about the epidemiology of CKDu in sub-Saharan Africa, due to the scarcity of renal biopsy and inadequate overall reporting. ${ }^{29}$

\section{Risk Factors and Pathogenesis}

The exact cause is unknown. However, different multifactorial etiologies like chronic exposure to dehydration, heat stress, agrochemicals, heavy metals, intake of fructose-rich drinks, frequent use of self-prescribed nonsteroidal anti-inflammatory drugs (NSAIDS), lower income and genetics were proposed in its development. Studies using geographical mapping also revealed that villages with a high prevalence of CKDu usually used irrigation water sources. $^{23,30-33}$ These risk factors are not mutually exclusive and they operate together, sequentially or simultaneously over a long period of time, causing acute and chronic manifestations of disease. ${ }^{4,18}$ Acute kidney injury (AKI) is a known etiological factor for consequent CKD, however, this progression has not been fully studied in the context of the natural history of CKDu. ${ }^{14,34}$ The major of these proposed risk factors with their pathogenesis were discussed in detail in the following sections.

\section{Heat Stress}

It is the combination of heat produced in the body and heat gained from the environment minus the heat lost from the body. ${ }^{35}$ The body's heat balance is decided by six factors: four climatic and two non-climatic. Heat stress develops in conjunction with dehydration and presents as a range of heat-related symptoms such as headache, fatigue, muscle cramps, weakness, dizziness, nausea, vomiting, tachycardia, hyperventilation, ataxia, and transient alteration in mental status. ${ }^{36}$ It affects both outdoor and indoor workers who carry out activities in hot environments. ${ }^{37}$

Repeated episodes of heat stress followed by dehydration can cause repeated subclinical ischemic kidney injury, which over time may lead to irreversible kidney injury and $\mathrm{CKDu}^{38}$ These repeated episodes of injury finally cause abnormal repair mechanisms, leading to vascular rarefication, renal fibrosis and glomerulo-sclerosis. ${ }^{39,40}$ Moreover, heat stress and dehydration could cause toxin-mediated kidney injury by accelerating reabsorption of toxins from low renal blood flow ${ }^{41}$ (Figure 1). An experimental study showed recurrent heat-induced dehydration leads to cortical urate accumulation, reduced GFR, proximal tubular injury, and fibrosis in mice. ${ }^{20}$ However, whether heat stress causes CKDu directly or indirectly is an intriguing idea, as it remains unconfirmed. ${ }^{40,42}$

Moreover, AKI caused by chronic dehydration and heat stress may be aggravated by other exposures like use of illegal alcohol, nephrotoxic drugs, rhabdomyolysis due to extreme labor, exposure to agrochemicals and heavy metals. ${ }^{4,43}$

\section{Dehydration}

Recurrent episodes of dehydration are the foremost likely cause of AKI. ${ }^{44}$ If the volume depletion is sustained, the GFR subsequently falls. This situation was at the beginning thought to be fully reversible with hydration, except if ischemia occurs. Subjects who are recurrently dehydrated may not eliminate toxins as efficiently as those who are well hydrated, resulting in higher concentrations of toxins within the blood serum and excretory organ resulting in excretory organ injury. ${ }^{45}$

Dehydration increases in urinary osmolality which activates aldose reductase pathway, converting glucose to fructose. In the proximal tubules, fructose is metabolized by fructokinase to urate, oxidants, and inflammatory mediators, causing tubular injury. Workers chew sugarcane and rehydrate with fructose-rich drinks, exacerbating the 


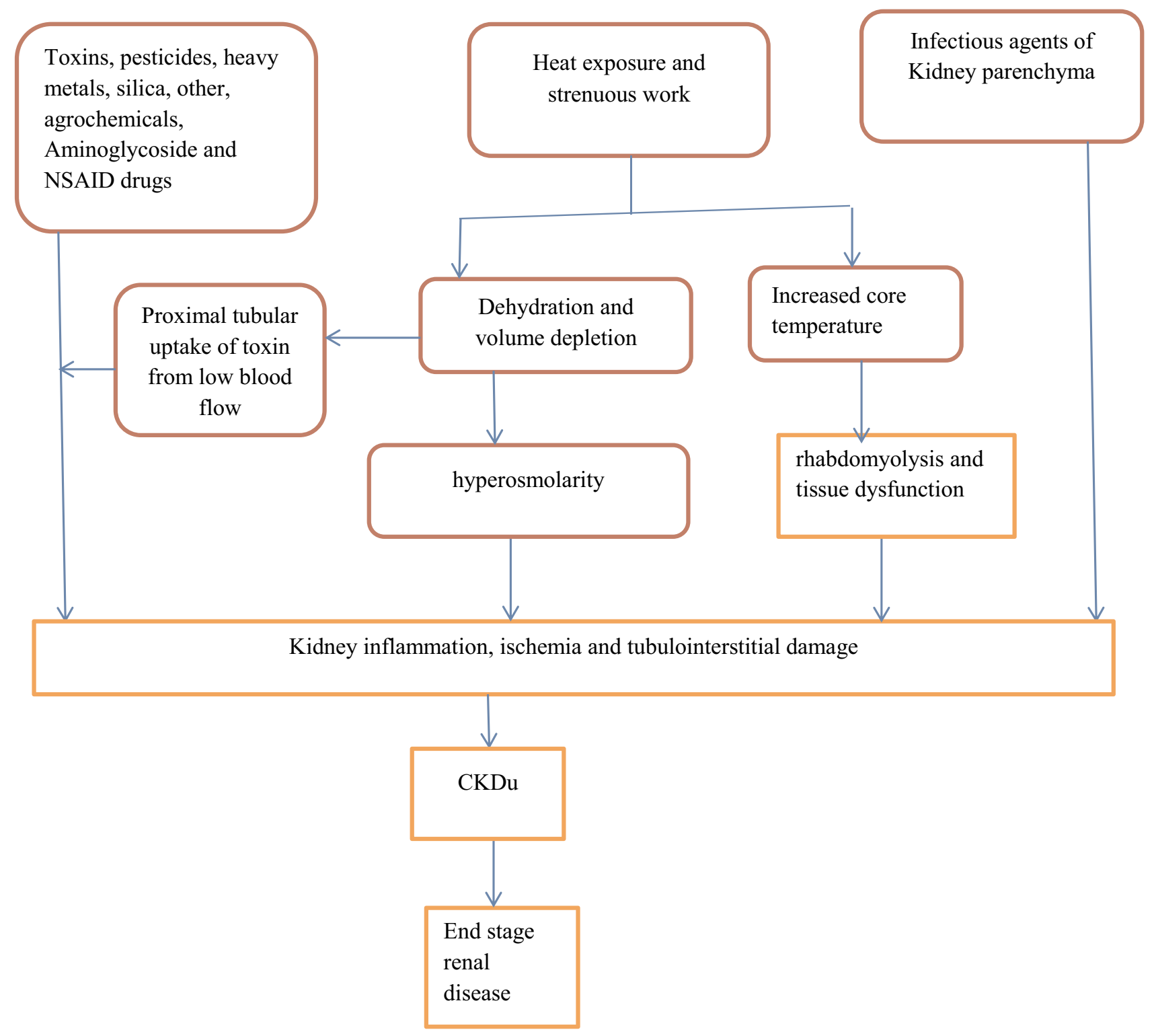

Figure I Probable mechanisms for the development of CKDu. Those includes (A) the uptake of toxins in the tubules, resulting in direct toxicity. (B) Heat exposure resulting in dehydration and rise in core temperature, which might cause kidney injury directly through tissue dysfunction or indirectly through rhabdomyolysis or hyperosmolarity. Furthermore, heat-associated dehydration may also cause kidney injury by strengthening the renal effects of toxins. (C) It has also been suggested that infectious agents may be involved in the pathogenesis of CKDu. For all mechanisms, genetic factors could be essential.

problem. $^{20,46}$ Hypovolemia also activates the reninangiotensin-aldosterone system (RAAS). Aldosterone release results in bicarbonate reabsorption in the distal renal tubule which can worsen aciduria ${ }^{47}$ and decreases renal absorption of potassium, which in turn causes decreased intra-renal perfusion pressure which can elicit renal tubular injury. ${ }^{40}$ In conclusion, recurrent and prolonged dehydration resulting from strenuous work in tropical climates is believed to lead to subclinical acute kidney injuries that develop into chronic damage over time. Furthermore, it has been identified as a causative factor that could lead to glomerular hypertension, interstitial fibrosis, and tubular injury due to the oxidative stress exerted onto the kidneys which could be a probable pathway leading to $\mathrm{CKDu}{ }^{40,48}$

\section{Role of Rhabdomyolysis}

Rhabdomyolysis results from the death of muscle fibers and release of its contents into the bloodstream. ${ }^{49}$ Strenuous work in hot climates causes subclinical rhabdomyolysis, exacerbating hyperuricemia and urinary urate can exceed its solubility and form microcrystals. ${ }^{50}$ Rhabdomyolysis is a well-known cause of AKI, and repeated exposure may lead to $\mathrm{CKDu} .{ }^{40}$ Muscle injury causes overproduction of uric acid and that hyperuricemia 
and uricosuria contribute to tubulointerstitial damage and may play a role in heat stress nephropathy. ${ }^{51,52}$ Workers who experience recurrent episodes of AKI may be at substantial risk of developing $\mathrm{CKDu}{ }^{53}$

\section{Leptospira Infection}

Leptospirosis is a prevalent zoonosis which can be transmitted to humans via soil or water contaminated by infected animal excreta, and people may be exposed to it during cultivation and harvesting tasks. The kidney is the main target organ of leptospira and the immune response is involved in the development of tubulointerstitial nephritis and tubular dysfunction in infected patients. ${ }^{54}$ The bacteria enter the kidney, ultimately penetrating the renal tubules to adhere to their inner surface. Even though it has not been established that acute leptospira infection leads to $\mathrm{CKDu}$, it might be a factor that increases vulnerability to $\mathrm{CKDu}{ }^{54,55}$ Probable mechanisms by which leptospirosis could lead to $\mathrm{CKDu}$ include: a) insidious kidney colonization by leptospira followed by a second hit to the kidney from heat stress and/or dehydration, and b) progression from leptospirosis-induced acute kidney injury. ${ }^{55}$

Leptospirosis is endemic in Sri Lanka and has been linked to CKDu and it is known to be a cause of AKI that can proceed to chronic renal failure. ${ }^{56}$ Several factors are involved in acute kidney injury (AKI) in leptospirosis, including direct nephrotoxic action of the leptospira, hyperbilirubinemia, rhabdomyolysis, and hypovolemia. ${ }^{57}$ Repeated leptospirosis infection is associated with both prevalence and severity of CKD. ${ }^{58}$ Recurrent leptospirosis has been shown to cause CKD in other mammals, although not yet confirmed in humans. ${ }^{25,59}$

\section{Genetic Factors}

Genetic factors may play a role in the CKDu epidemic, as some studies have suggested association between family history of CKD and CKDu. ${ }^{60,61}$ Studies in Sri Lanka showed known polymorphisms in SLC13A3 (sodiumdependent dicarboxylate transporter member 3$)^{33}$ and KCNA10 gene, which encode for a voltage-gated potassium channel found in proximal tubular cells ${ }^{62}$ were related to renal disorder. Moreover, in Sri Lanka and India, there are specific polymorphisms and singlenucleotide mutations which have been related to $\mathrm{CKDu}$ in some endemic communities. ${ }^{33,63}$

\section{Socio-Economic Factors and Water Quality}

Factors like lack of rest breaks, low wages, lack of safe water, use of clothing that increases body heat, lower daily fluid intake and lack of sufficient workplace regulation, which necessitate workers to work in difficult conditions promote the development of CKDu. ${ }^{64,65}$

There is also a study which suggests that water quality is a causative factor in the development of CKDu. The majority of people living in affected areas consume domestic stagnant water which does not communicate with deep tube wells. Communities that drink water from shallow wells in close proximity to irrigation systems developed for agriculture with demonstrable seepage from irrigation system to the wells are more affected by CKDu compared to communities without irrigation seepage into wells. In contrast, communities living in geographical close proximity to irrigation systems who get drinking water from wells sourced by natural springs appear to be less affected by $\mathrm{CKDu}{ }^{32}$

Drinking ground hard water in the endemic areas with high fluoride concentrations and calcium is proposed as risk factors for $\mathrm{CKDu},{ }^{42,65,67}$ but not all areas with hardness in ground water are affected. ${ }^{68}$ According to Wanigasuriya et al's study, participants who drank well water in the field were roughly 2.5 times more likely to have microalbuminuria than their counterparts. ${ }^{69}$ Furthermore, according to an experimental study, high fluoride and other undetected toxins in shallow-dug wells may be causative factors for $\mathrm{CKDu}^{70}$ Chandrajith et al suggested that hard water could enhance the cytotoxic properties of fluoride. ${ }^{71}$ Fluoride in water has been raised as a possible cause of $\mathrm{CKDu}$ in Sri Lanka, but this hypothesis remains highly speculative. ${ }^{72}$ An experimental study revealed hard water with high fluoride content resulted in acute tubular injury and it can be minimized by administering distilled water. ${ }^{73}$ In addition, high silica levels in drinking water from pesticides containing silica or as a result of leaching from bed rocks and the combination of silica, strontium and NSAIDs have been proposed to cause $\mathrm{CKDu}{ }^{74}$

\section{Agrochemicals and Nephrotoxic Exposure}

Agrochemicals like fertilizers and pesticides have been assumed as risk factors for CKDu. ${ }^{41,75}$ Agricultural workers are exposed to agrochemicals via inhalation, ingestion, and dermal contact. Agrochemicals such as glyphosate, paraquat or heavy metals such as lead, arsenic, cadmium, 
uranium and silica have been associated with CKDu; however, as of today, there is no proven cause-effect relationship. ${ }^{60,68,76}$ Arsenic and cadmium are released into the environment byphosphorous fertilizers and glyphosate is released through herbicides added for the harvesting process. In Sri Lanka, increased levels of glyphosate are present in farm-lands' topsoil, indicating prolonged exposure which can be one of the causative agents for $\mathrm{CKDu}{ }^{77}$

Despite the fact that the WHO considered pesticides containing arsenic as hazardous, many farmers still continue to use them as they are unaware of the harm caused by these heavy metals. ${ }^{78}$ European Union passed a bill to limit the use of cadmium-containing fertilizers. ${ }^{79}$ The patho-physiological mechanisms behind heavy metalinduced kidney injury are complex and some aspects of their metabolism and mechanisms of toxicity remain unknown and there was no evidence to support their direct contribution in pathogenesis of $\mathrm{CKDu}$ and the most plausible mechanism is related to oxidative stress and inflammatory processes. ${ }^{80}$ Heavy metals, most particularly cadmium and arsenic, have been potentially related to $\mathrm{CKDu}^{69}$ However, in a longitudinal cohort study in Nicaragua, agrochemical applicators did not have a significant increase in renal injury biomarkers. ${ }^{81}$

Contact with and inhalation of pesticides have been proposed as a risk factor for $\mathrm{CKDu},{ }^{75}$ but not all reports have supported the association between pesticides and CKDu. For instance, a systematic review by GonzálezQuiroz et $\mathrm{al}^{60}$ and a study in Nicaragua did not find an association between $\mathrm{CKDu}$ and exposure to pesticides. ${ }^{82}$ However, a study in the US reported an association between pesticide exposure and ESRD. ${ }^{83}$

\section{Other Possible Causes}

Other possible risk factors reported include long-term use of aminoglycoside antibiotics, ${ }^{38}$ alcohol use, history of malaria, tobacco smoke and intake of fructose-rich soft drinks which are largely anecdotal. ${ }^{72,83,84}$ Hantavirus is another rodent-borne pathogen that has been proposed as a possible causal agent in $\mathrm{CKDu},{ }^{85,86}$ and male predominance may be due to occupational exposures that are related to gender differences, such as strenuous work done mostly by men and not to sex differences. ${ }^{87}$

\section{Clinical Features}

It has no clear early clinical signs and it is unclear from CKD because of different causes. ${ }^{12}$ The typical clinical presentation of $\mathrm{CKDu}$ is a young male from an endemic coastal hotspot with a family history of CKD. Clinically $\mathrm{CKDu}$ is described as normal or slightly elevated blood pressure, low-grade non-nephrotic proteinuria and decreased GFR ${ }^{51,88,89}$ Hypertension, anemia and edema ensue late in the disease progression. Symptoms include lack of appetite, fatigue, recurrent dysuria, urgency, and back pain. ${ }^{52,76}$ These symptoms are often misdiagnosed as urinary tract infections and treated with drugs like aminoglycosides which are potentially nephrotoxic. ${ }^{90}$

Kidney biopsies have shown evidence of acute injury like interstitial edema, acute tubular cell injury, and early fibrosis and chronic injury like tubular atrophy, interstitial fibrosis with associated secondary glomerulo-sclerosis and signs of glomerular ischemia. ${ }^{4,14}$ Renal scarring was not common, usually tubulointerstitial changes predominate over glomerular and vascular changes. The major affected parts are proximal tubules and the interstitium part of kidney. Tubular atrophy and interstitial fibrosis were frequently seen. ${ }^{25}$ Changes characteristic of diabetes and immune deposits have not been seen and indications of hypertensive disease have been insignificant or minimal. ${ }^{91,92}$ The urinalysis reveals no or minimal proteinuria, small numbers of red cells and leukocytes, and occasionally amorphous urate crystals. Serum electrolyte abnormalities may include hyponatremia, hypokalemia, and hypomagnesemia., ${ }^{8,12}$ Ultrasound at initial stages showed normal-sized kidneys and increased echogenicity of the parenchyma. ${ }^{88}$

Histopathological investigation of renal biopsies shows glomerular and interstitial changes that are compatible with recurrent episodes of ischemia. ${ }^{93}$

\section{At Risk Groups}

It mainly affects primarily socially vulnerable communities, those who regularly work in hot conditions of the tropics. Working-age male agricultural workers who perform strenuous labor are the worst affected. The possible explanation is because they perform harsh physical labor in hot climatic conditions that result in chronic dehydration. ${ }^{12}$ According to some studies, progression to CKD occurred in $8.4 \%$ of 586 sugarcane workers with AKI. ${ }^{14,94}$ Sugarcane workers are particularly at risk of heat stress and dehydration due to the lack of shade, heavy exertion for hours, and lack of access to sufficient drinking water during the workday. ${ }^{36}$ Sugarcane seed cutters have the highest prevalence, although other "hot" occupations such as port workers, rice farmers, miners, and cotton and construction workers are also affected. ${ }^{13,59,95}$ 


\section{Treatment}

No explicit treatment guidelines were present. Patients in whom nephropathy progresses to ESRD will need dialysis or transplantation. According to some studies allopurinol may provide protection against heat stress-induced renal injury. ${ }^{96,97}$ Allopurinol decreases C-reactive protein and slows down the progression of renal disease in patients with chronic kidney disease by lowering uric acid in hyperuricemic subjects. ${ }^{98}$ There is inadequate evidence at the present time to support the use of pharmacotherapy to avoid progressive kidney function decline in CKDu. Because of the tendency toward volume depletion, reninangiotensin inhibitors should be used cautiously; but there is no firm evidence of their benefit. However, use of angiotensin converting enzyme inhibitors, and angiotensin receptor blockers, allopurinol, and corticosteroids and other medications in appropriate clinical situations arising concurrently with CKDu may be appropriate for some patients. Mild to moderate hypokalemia is managed with fruit-rich diet and spironolactone. ${ }^{99,100}$ In addition, according to some studies, sodium bicarbonate delays the progression of $\mathrm{CKD}^{96,101}$ and one experimental study has demonstrated its protective role in preventing kidney injury from repeated heat stress. ${ }^{102}$

\section{Prevention}

Preventive measures are focused on risk factors, screening at-risk populations. Early diagnosis and appropriate interventions are paramount. Since there is no convincing etiology, the assumed causal factors are potentially preventable. Those prevention methods include: provision of safe drinking water, avoidance of nephrotoxic drugs, reduce exposure to toxins and improve working conditions. ${ }^{103}$ Moreover, WHO and the Food and Agriculture Organization of the United Nations have made strong recommendations including quality control for fertilizers, compulsory provision of personal protective equipment for agrochemical sale and use, tighter regulation on sales of agrochemicals thought to be nephrotoxic and improving health education. In addition, mapping of high-prevalence areas using geographical information systems used to identify high risk groups of the population is essential.

\section{Future Directions}

In general, despite several hypotheses being considered, the risk factors, pathophysiological mechanisms, diagnostic methods and treatment of CKDu are not explicitly established. ${ }^{104}$
Hence, there is a need for well-designed, more conclusive studies examining causation, clear pathogenesis, and validation of more sensitive biomarkers to unravel the mystery of this disease.

\section{Conclusion and Recommendation}

Chronic kidney disease of unknown etiology is a serious novel cause for kidney failure and leads to premature death, particularly among disadvantaged populations around the tropics. It is characterized by slowly progressing and frequently asymptomatic disease until advanced stage and it is not attributable to known etiologies of CKD. The highest burden of the disease is seen in lower income, male agricultural population of the tropics. Despite several hypotheses present, no explicit causative agent has been conclusively established. Early recognition and management at the earliest possible stage are key for reducing its associated morbidity and mortality. Biomarkers that are tubular-specific can be specific and sensitive for screening and early diagnosis of CKDu. The dominant histopathological feature was chronic tubulointerstitial nephritis.

Preventive measures include health promotion at individual and community screening campaigns to increase awareness, early diagnosis and timely management of it. A comprehensive approach with an emphasis on awareness, prevention, screening, surveillance and strengthening of healthcare infrastructure to increase access to medical care and establishment of management is essential.

\section{Funding}

No funding was available for this work.

\section{Disclosure}

The author reports no conflicts of interest for this work.

\section{References}

1. Webster AC, Nagler EV, Morton RL, Masson P. Chronic kidney disease. Lancet. 2017;389(10075):1238-1252. doi:10.1016/S01406736(16)32064-5

2. Ene-Iordache B, Perico N, Bikbov B, et al. Chronic kidney disease and cardiovascular risk in six regions of the world (ISN-KDDC): a cross-sectional study. Lancet Glob Health. 2016;4(5):e307-19. doi:10.1016/S2214-109X(16)00071-1

3. Couser WG, Remuzzi G, Mendis S, Tonelli M. The contribution of chronic kidney disease to the global burden of major non-communicable diseases. Kidney Int. 2011;80(12):1258-1270. doi:10.1038/ki.2011.368

4. Correa-Rotter R, Wesseling C, Johnson RJ. CKD of unknown origin in Central America: the case for a Mesoamerican nephropathy. $A m$ J Kidney Dis. 2014;63(3):506-520. doi:10.1053/j.ajkd.2013.10.062

5. Rodríguez MI. Sounding the alarm on chronic kidney disease in farming communities: María Isabel Rodríguez MD. Minister of health, El Salvador. Interview by Conner Gorry. MEDICC Rev. 2013;15(3):8. 
6. Rajapurkar MM, John GT, Kirpalani AL, et al. What do we know about chronic kidney disease in India: first report of the Indian CKD registry. BMC Nephrol. 2012;13(1):10. doi:10.1186/14712369-13-10

7. Tuot DS, Zhu Y, Velasquez A, et al. Variation in patients' awareness of CKD according to how they are asked. Clin J Am Soc Nephrol. 2016;11(9):1566-1573. doi:10.2215/CJN.00490116

8. Herrera R, Orantes CM, Almaguer M, et al. Clinical characteristics of chronic kidney disease of nontraditional causes in Salvadoran farming communities. MEDICC Rev. 2014;16:39-48.

9. Levin A, Stevens PE, Bilous RW, et al. KDIGO 2012 clinical practice guideline for the evaluation and management of chronic kidney disease. Kidney Int Suppl. 2013;3(1):1-50.

10. Caplin B, Yang CW, Anand S, et al. The international society of nephrology's international consortium of collaborators on chronic kidney disease of unknown etiology: report of the working group on approaches to population-level detection strategies and recommendations for a minimum dataset. Kidney Int. 2019;95(1):4-10. doi:10.1016/j.kint.2018.08.019

11. Pan American Health Organization. Epidemic of chronic kidney disease in agricultural communities in Central America. Case definitions, methodological basis and approaches for public health surveillance. Washington, DC: Pan American Health Organization; 2017. Available from: http://iris.paho.org/xmlui/han dle/123456789/34132. Accessed November 30, 2020.

12. Athuraliya NT, Abeysekera TD, Amerasinghe PH, et al. Uncertain etiologies of proteinuric-chronic kidney disease in rural Sri Lanka. Kidney Int. 2011;80(11):1212-1221. doi:10.1038/ki.2011.258

13. Ramirez-Rubio O, McClean MD, Amador JJ, Brooks DR. An Epidemic of Chronic Kidney Disease in Central America: An Overview. 2013:123-125.

14. Fischer RS, Vangala C, Truong L, et al. Early detection of acute tubulointerstitial nephritis in the genesis of Mesoamerican nephropathy. Kidney Int. 2018;93(3):681-690. doi:10.1016/j. kint.2017.09.012

15. Fischer RS, Mandayam S, Chavarria D, et al. Clinical evidence of acute Mesoamerican nephropathy. Am J Trop Med Hyg. 2017;97 (4):1247-1256. doi:10.4269/ajtmh.17-0260

16. Fischer RS, Vangala $\mathrm{C}$, Mandayam $\mathrm{S}$, et al. Clinical markers to predict progression from acute to chronic kidney disease in Mesoamerican nephropathy. Kidney Int. 2018;94(6):1205-1216. doi:10.1016/j.kint.2018.08.020

17. Senevirathna L, Abeysekera T, Nanayakkara S, et al. Risk factors associated with disease progression and mortality in chronic kidney disease of uncertain etiology: a cohort study in Medawachchiya, Sri Lanka. Environ Health Prev Med. 2012;17(3):191-198. doi:10.1007/s12199-011-0237-7

18. Jayasekara KB, Kulasooriya PN, Wijayasiri KN, et al. Relevance of heat stress and dehydration to chronic kidney disease $(\mathrm{CKDu})$ in Sri Lanka. Prev Med Rep. 2019;1(15):100928. doi:10.1016/j.pmedr.2019.100928

19. Abeyagunawardena AS, Shroff R. CKDu: The Known Unknowns. Pediatric Nephrology (Berlin, Germany). 2020.

20. Jimenez CA, Ishimoto T, Lanaspa MA, et al. Fructokinase activity mediates dehydration-induced renal injury. Kidney Int. 2014;86 (2):294-302. doi:10.1038/ki.2013.492

21. Ratnayake S, Badurdeen Z, Nanayakkara N, Abeysekara T, Ratnatunga N, Kumarasiri R. Screening for chronic kidney disease of uncertain aetiology in Sri Lanka: usability of surrogate biomarkers over dipstick proteinuria. BMC Nephrol. 2017;18(1):199. doi:10.1186/s12882-017-0610-x

22. De Silva PM, Mohammed Abdul KS, Eakanayake EM, Jayasinghe SS, Jayasumana C, Asanthi HB. Urinary biomarkers KIM-1 and NGAL for detection of chronic kidney disease of uncertain etiology $(\mathrm{CKDu})$ among agricultural communities in Sri Lanka. PLOS Negl Trop Dis. 2016;10(9):e0004979. doi:10.1371/ journal.pntd.0004979
23. Elledge MF, Redmon JH, Levine KE, Wickremasinghe RJ, Wanigasariya KP, Peiris-John RJ. Chronic kidney disease of unknown etiology in Sri Lanka: quest for understanding and global implications. In: RTI Press Research Brief [Internet]. RTI press; 2014.

24. Gifford FJ, Gifford RM, Eddleston M, Dhaun N. Endemic nephropathy around the world. Kidney Int Rep. 2017;2(2):282-292. doi:10.1016/j.ekir.2016.11.003

25. Abraham G, Varughese $S$, Thandavan $T$, et al. Chronic kidney disease hotspots in developing countries in South Asia. Clin Kidney J. 2016;9(1):135-141. doi:10.1093/ckj/sfv109

26. Ramírez-Rubio O, Amador JJ, Kaufman JS, et al. Urine biomarkers of kidney injury among adolescents in Nicaragua, a region affected by an epidemic of chronic kidney disease of unknown aetiology. Nephrol Dial Transplant. 2016;31(3):424-432. doi:10.1093/ndt/ gfv292

27. Cuadra S, Hogstedt C, Jakobsson K, et al. Chronic kidney disease: assessment of current knowledge and feasibility for regional research collaboration in Central America. Available from: http:// www.iret.una.ac.cr/Publications/01-0008.pdf.

28. Wesseling C, de Joode BV, Crowe J, et al. Mesoamerican nephropathy: geographical distribution and time trends of chronic kidney disease mortality between 1970 and 2012 in Costa Rica. Occup Environ Med. 2015;72(10):714-721. doi:10.1136/oemed-2014102799

29. Stanifer JW, Jing B, Tolan S, et al. The epidemiology of chronic kidney disease in sub-Saharan Africa: a systematic review and meta-analysis. Lancet Glob Health. 2014;2(3):e174-81. doi:10. 1016/S2214-109X(14)70002-6

30. Valcke M, Levasseur ME, da Silva AS, Wesseling C. Pesticide exposures and chronic kidney disease of unknown etiology: an epidemiologic review. Environ Health. 2017;16(1):49. doi:10. 1186/s12940-017-0254-0

31. Wesseling C, Aragón A, González M, et al. Heat stress, hydration and uric acid: a cross-sectional study in workers of three occupations in a hotspot of Mesoamerican nephropathy in Nicaragua. BMJ Open. 2016;6(12):e011034. doi:10.1136/bmjopen-2016-011034

32. Jayasekara JM, Dissanayake DM, Adhikari SB, Bandara P. Geographical distribution of chronic kidney disease of unknown origin in North Central Region of Sri Lanka. Ceylon Med J. 2013;58(1):6-10. doi:10.4038/cmj.v58i1.5356

33. Nanayakkara S, Stmld S, Abeysekera T, et al. An integrative study of the genetic, social and environmental determinants of chronic kidney disease characterized by tubulointerstitial damages in the North Central Region of Sri Lanka. J Occup Health. 2013;13-0172.

34. Beker BM, Corleto MG, Fieiras C, Musso CG. Novel acute kidney injury biomarkers: their characteristics, utility and concerns. Int Urol Nephrol. 2018;50(4):705-713. doi:10.1007/s11255-017-1781-x

35. Health (US), Centers for Disease Control, Prevention (US), Human Services Dept (US). editors. NIOSH Criteria for a Recommended Standard: Occupational Exposure to Heat and Hot Environments. National Institute on Drug Abuse; 2018.

36. Crowe J, Nilsson M, Kjellstrom T, Wesseling C. Heat-related symptoms in sugarcane harvesters. Am J Ind Med. 2015;58 (5):541-548. doi:10.1002/ajim.22450

37. Lundgren K, Kuklane K, Gao C, Holmer I. Effects of heat stress on working populations when facing climate change. Ind Health. 2013;51(1):3-15. doi:10.2486/indhealth.2012-0089

38. Wesseling C, Crowe J, Hogstedt C, Jakobsson K, Lucas R, Wegman DH. Resolving the enigma of the mesoamerican nephropathy: a research workshop summary. Am J Kidney Dis. 2014;63 (3):396-404. doi:10.1053/j.ajkd.2013.08.014

39. Venkatachalam MA, Weinberg JM, Kriz W, Bidani AK. Failed tubule recovery, AKI-CKD transition, and kidney disease progression. J Am Soc Nephrol. 2015;26(8):1765-1776. doi:10. 1681/ASN.2015010006 
40. Glaser J, Lemery J, Rajagopalan B, et al. Climate change and the emergent epidemic of CKD from heat stress in rural communities: the case for heat stress nephropathy. Clin J Am Soc Nephrol. 2016;11(8):1472-1483. doi:10.2215/CJN.13841215

41. Jayasumana C, Orantes C, Herrera R, et al. Chronic interstitial nephritis in agricultural communities: a worldwide epidemic with social, occupational and environmental determinants. Nephrol Dial Transplant. 2017;32(2):234-241.

42. Redmon JH, Elledge MF, Womack DS, et al. Additional perspectives on chronic kidney disease of unknown aetiology (CKDu) in Sri Lanka-lessons learned from the WHO CKDu population prevalence study. BMC Nephrol. 2014;15(1):1. doi:10.1186/1471-2369-15-125

43. Levin A, Tonelli M, Bonventre J, et al. Global kidney health 2017 and beyond: a roadmap for closing gaps in care, research, and policy. Lancet. 2017;390(10105):1888-1917. doi:10.1016/S01406736(17)30788-2

44. Johnson RJ, Sánchez-Lozada LG. Mesoamerican nephropathynew clues to the cause. Nat Rev Nephrol. 2013;9(10):560-561. doi:10.1038/nrneph.2013.174

45. Roncal-Jimenez C, Lanaspa MA, Jensen T, Sanchez-Lozada LG, Johnson RJ. Mechanisms by which dehydration may lead to chronic kidney disease. Ann Nutr Metab. 2015;66(Suppl. 3):10-13. doi:10.1159/000381239

46. Jimenez CR, Ishimoto T, Lanaspa MA, et al. Dehydration-induced renal Injury: a fructokinase mediated disease? Kidney Int. 2013.

47. García-Trabanino R, Jarquín E, Wesseling C, et al. Heat stress, dehydration, and kidney function in sugarcane cutters in El Salvador-a cross-shift study of workers at risk of Mesoamerican nephropathy. Environ Res. 2015;1(142):746-755. doi:10.1016/j. envres.2015.07.007

48. Rojas-Valverde D, Olcina GJ, Gutierrez Vargas R, Crowe J. Heat strain, external workload and chronic kidney disease in tropical settings: are endurance athletes exposed? Front Physiol. 2019;10:1403. doi:10.3389/fphys.2019.01403

49. Petejova N, Martinek A. Acute kidney injury due to rhabdomyolysis and renal replacement therapy: a critical review. Crit Care. 2014;18(3):224. doi:10.1186/cc13897

50. Roncal-Jimenez C, García-Trabanino R, Barregard L, et al. Heat stress nephropathy from exercise-induced uric acid crystalluria: a perspective on Mesoamerican nephropathy. Am J Kidney Dis. 2016;67(1):20-30. doi:10.1053/j.ajkd.2015.08.021

51. Madero M, García-Arroyo FE, Sánchez-Lozada LG. Pathophysiologic insight into MesoAmerican nephropathy. Curr Opin Nephrol Hypertens. 2017;26(4):296-302. doi:10.1097/MNH.0000000000000331

52. Selvarajah M, Weeratunga P, Sivayoganthan S, Rathnatunga N, Rajapakse S. Clinico pathological correlates of chronic kidney disease of unknown etiology in Sri Lanka. Indian J Nephrol. 2016;26(5):357. doi:10.4103/0971-4065.167280

53. Vos T, Abajobir AA, Abate KH, et al. Global, regional, and national incidence, prevalence, and years lived with disability for 328 diseases and injuries for 195 countries, 1990-2016: a systematic analysis for the global burden of disease study 2016. Lancet. 2017;390 (10100):1211-1259.

54. Seguro AC, Andrade L. Pathophysiology of leptospirosis. Shock 2013;1(39):17-23. doi:10.1097/SHK.0b013e31828fae49

55. Yang CW. Leptospirosis renal disease: emerging culprit of chronic kidney disease unknown etiology. Nephron. 2018;138(2):129-136. doi:10.1159/000480691

56. Gamage CD, Sarathkumara YD. Chronic kidney disease of uncertain etiology in Sri Lanka: are leptospirosis and hantaviral infection likely causes? Med Hypotheses. 2016;1(91):16-19. doi:10.1016/j. mehy.2016.04.009

57. Daher FE. Leptospirosis-associated acute kidney injury. J Bras Nefrol. 2010;32(4):400-407.
58. Yang HY, Hung CC, Liu SH, et al. Overlooked risk for chronic kidney disease after leptospiral infection: a population-based survey and epidemiological cohort evidence. PLoS Negl Trop Dis. 2015;9(10):e0004105. doi:10.1371/journal.pntd.0004105

59. Wesseling C, Crowe J, Hogstedt C, Jakobsson K, Lucas R, Wegman D. Mesoamerican nephropathy: report from the first international research workshop on MeN. Heredia: SALTRA, IRETUNA; 2013. Available from: http://www.regionalnephropathy.org/ wp-content/uploads/2013/04/Techn.

60. González-Quiroz M, Pearce N, Caplin B, Nitsch D. What do epidemiological studies tell us about chronic kidney disease of undetermined cause in Meso-America? A systematic review and meta-analysis. Clin Kidney J. 2018;11(4):496-506. doi:10.1093/ $\mathrm{ckj} / \mathrm{sfx} 136$

61. Chandrajith R, Nanayakkara S, Itai K, et al. Chronic kidney diseases of uncertain etiology (CKDue) in Sri Lanka: geographic distribution and environmental implications. Environ Geochem Health. 2011;33(3):267-278. doi:10.1007/s10653-010-9339-1

62. Nanayakkara S, Senevirathna ST, Parahitiyawa NB, et al. Wholeexome sequencing reveals genetic variants associated with chronic kidney disease characterized by tubulointerstitial damages in North Central Region, Sri Lanka. Environ Health Prev Med. 2015;20 (5):354-359. doi:10.1007/s12199-015-0475-1

63. Siddarth M, Datta SK, Ahmed RS, Banerjee BD, Kalra OP, Tripathi AK. Association of CYP1A1 gene polymorphism with chronic kidney disease: a case control study. Environ Toxicol Pharmacol. 2013;36(1):164-170. doi:10.1016/j.etap.2013.03.008

64. Brooks CJ, Gortmaker SL, Long MW, Cradock AL, Kenney EL. Racial/ethnic and socioeconomic disparities in hydration status among US adults and the role of tap water and other beverage intake. Am J Public Health. 2017;107(9):1387-1394. doi:10.2105/ AJPH.2017.303923

65. Bodin T, García-Trabanino R, Weiss I, et al. Intervention to reduce heat stress and improve efficiency among sugarcane workers in El Salvador: Phase 1. Occup Environ Med. 2016;73(6):409-416.

66. Balasooriya S, Munasinghe H, Herath AT, et al. Possible links between groundwater geochemistry and chronic kidney disease of unknown etiology (CKDu): an investigation from the Ginnoruwa region in Sri Lanka. Expos Health. 2019;17:1-2.

67. Nanayakkara S, Senevirathna ST, Harada KH, et al. Systematic evaluation of exposure to trace elements and minerals in patients with chronic kidney disease of uncertain etiology (CKDu) in Sri Lanka. J Trace Elem Med Biol. 2019;1(54):206-213. doi:10.1016/j. jtemb.2019.04.019

68. Jayasumana C, Gunatilake S, Senanayake P. Glyphosate, hard water and nephrotoxic metals: are they the culprits behind the epidemic of chronic kidney disease of unknown etiology in Sri Lanka? Int J Environ Res Public Health. 2014;11(2):2125-2147. doi:10. 3390/ijerph110202125

69. Wanigasuriya KP, Peiris-John RJ, Wickremasinghe R. Chronic kidney disease of unknown aetiology in Sri Lanka: is cadmium a likely cause? BMC Nephrol. 2011;12(1):32. doi:10.1186/14712369-12-32

70. Thammitiyagodage MG, Gunatillaka MM, Ekanayaka N, et al. Ingestion of dug well water from an area with high prevalence of chronic kidney disease of unknown etiology (CKDu) and development of kidney and liver lesions in rats. Ceylon Med J. 2017;62 (1):20. doi:10.4038/cmj.v62i1.8428

71. Chandrajith R, Dissanayake CB, Ariyarathna T, Herath HM, Padmasiri JP. Dose-dependent $\mathrm{Na}$ and $\mathrm{Ca}$ in fluoride-rich drinking water - another major cause of chronic renal failure in tropical arid regions. Sci Total Environ. 2011;409(4):671-675. doi:10.1016/j. scitotenv.2010.10.046 
72. International expert consultation on chronic kidney disease of unknown etiology [Internet]. World Health Organization, Country Office for Sri Lanka; 2016 [cited Nov 20, 2020]. Available from: https://apps.who.int/iris/handle/10665/255137.

73. Perera T, Ranasinghe S, Alles N, Waduge R. Experimental rat model for acute tubular injury induced by high water hardness and high water fluoride: efficacy of primary preventive intervention by distilled water administration. BMC Nephrol. 2020;21(1):1-6. doi:10.1186/s12882-020-01763-3

74. Khandare AL, Reddy YS, Balakrishna N, Rao GS, Gangadhar T, Arlappa N. Role of drinking water with high silica and strontium in chronic kidney disease: an exploratory community-based study in an Indian Village. Indian $J$ Community Health. 2015;27(1):95-102.

75. Raines N, González M, Wyatt C, et al. Risk factors for reduced glomerular filtration rate in a Nicaraguan community affected by Mesoamerican nephropathy. MEDICC Rev. 2014;16:16-22.

76. McClean M, Amador JJ, Laws R, et al. Biological Sampling Report: Investigating Biomarkers of Kidney Injury and Chronic Kidney Disease Among Workers in Western Nicaragua. Boston: University School of Public Health: Compliance Advisor Ombudman; 2012.

77. Baran MJ, Cibiński M. Glyphosate-based phospho-organic herbicides-an outline of action, metabolism and the selected effects on humans and other organisms. Arch Physiother Glob Res. 2014;18 (1):35-45. doi:10.15442/apgr.19.2.10

78. Jayasumana C, Fonseka S, Fernando A, et al. Phosphate fertilizer is a main source of arsenic in areas affected with chronic kidney disease of unknown etiology in Sri Lanka. SpringerPlus. 2015;4 (1):90. doi:10.1186/s40064-015-0868-z

79. Zheng L, Kuo CC, Fadrowski J, Agnew J, Weaver VM, NavasAcien A. Arsenic and chronic kidney disease: a systematic review. Curr Environ Health Rep. 2014;1(3):192-207. doi:10.1007/s40572014-0024-x

80. Bánfalvi G. Cellular Effects of Heavy Metals. New York: Springer; 2011.

81. Laws RL, Brooks DR, Amador JJ, et al. Biomarkers of kidney injury among Nicaraguan sugarcane workers. Am J Kidney Dis. 2016;67(2):209-217. doi:10.1053/j.ajkd.2015.08.022

82. Sanoff SL, Callejas L, Alonso CD, et al. Positive association of renal insufficiency with agriculture employment and unregulated alcohol consumption in Nicaragua. Ren Fail. 2010;32(7):766-777. doi:10.3109/0886022X.2010.494333

83. Lebov JF, Engel LS, Richardson D, Hogan SL, Hoppin JA, Sandler DP. Pesticide use and risk of end-stage renal disease among licensed pesticide applicators in the agricultural health study. Occup Environ Med. 2016;73(1):3-12. doi:10.1136/oemed2014-102615

84. Siriwardhana EA, Perera PA, Sivakanesan R, Abeysekara T, Nugegoda DB, Jayaweera JA. Dehydration and malaria augment the risk of developing chronic kidney disease in Sri Lanka. Indian $J$ Nephrol. 2015;25(3):146. doi:10.4103/0971-4065. 140712

85. Murray KO, Fischer RSB, Chavarria D, Christiane Duttmann MN, Garcia RG, Peter J. Mesoamerican Nephropathy: A Neglected Tropical Disease with an Infectious Etiology? 2015:671-675.

86. Gamage CD, Yoshimatsu K, Sarathkumara YD, Kulendiran T, Nanayakkara N, Arikawa J. Serological evidence of hantavirus infection in Girandurukotte, an area endemic for chronic kidney disease of unknown aetiology $(\mathrm{CKDu})$ in Sri Lanka. Int $J$ Infect Dis. 2017;1(57):77-78. doi:10.1016/j.ijid.2017.02.004

87. Peraza S, Wesseling C, Aragon A, et al. Decreased kidney function among agricultural workers in El Salvador. Am J Kidney Dis. 2012;59(4):531-540. doi:10.1053/j.ajkd.2011.11.039
88. Wijkström J, Leiva R, Elinder CG, et al. Clinical and pathological characterization of Mesoamerican nephropathy: a new kidney disease in Central America. Am J Kidney Dis. 2013;62(5):908-918. doi:10.1053/j.ajkd.2013.05.019

89. Nanayakkara S, Senevirathna ST, Karunaratne U, et al. Evidence of tubular damage in the very early stage of chronic kidney disease of uncertain etiology in the north central province of Sri Lanka: a cross-sectional study. Environ Health Prev Med. 2012;17 (2):109-117. doi:10.1007/s12199-011-0224-z

90. Brooks D, McClean M. Boston University Investigation of Chronic Kidney Disease in Western Nicaragua, 2009-2012. Boston, MA: Boston University School of Public Health; 2012.

91. Wijkström J, Jayasumana C, Dassanayake R, et al. Morphological and clinical findings in Sri Lankan patients with chronic kidney disease of unknown cause $(\mathrm{CKDu})$ : similarities and differences with Mesoamerican nephropathy. PLoS One. 2018;13(3): e0193056. doi:10.1371/journal.pone.0193056

92. López-Marín L, Chávez Y, García XA, et al. Histopathology of chronic kidney disease of unknown etiology in Salvadoran agricultural communities. MEDICC Rev. 2014;16:49-54.

93. Elinder CG, Wernerson A, Wijkstrom J. Mesoamerican nephropathy $(\mathrm{MeN})$. A "new" chronic kidney disease related to occupational heat exposure with repeated deprivation of salts and water. Int J Nephrol Kidney Fail. 2015;1(2):1-9.

94. Watts N, Adger WN, Ayeb-Karlsson S, et al. The lancet countdown: tracking progress on health and climate change. Lancet. 2017;389(10074):1151-1164. doi:10.1016/S0140-6736(16)32124-9

95. Wegman D, Crowe J, Hogstedt C, Jakobsson K, Wesseling C. Mesoamerican Nephropathy: Report from the Second International Research Workshop on MeN. 2016.

96. Roncal-Jimenez CA, Sato Y, Milagres T, et al. Experimental heat stress nephropathy and liver injury are improved by allopurinol. $\mathrm{Am}$ J Physiol Renal Physiol. 2018;315(3):F726-33. doi:10.1152/ ajprenal.00543.2017

97. Rajapakse S, Shivanthan MC, Selvarajah M. Chronic kidney disease of unknown etiology in Sri Lanka. Int J Occup Environ Health. 2016;22(3):259-264. doi:10.1080/10773525.2016.1203097

98. Goicoechea M, de Vinuesa SG, Verdalles U, et al. Effect of allopurinol in chronic kidney disease progression and cardiovascular risk. Clin J Am Soc Nephrol. 2010;5(8):1388-1393. doi:10.2215/ CJN.01580210

99. Johnson RJ, Wesseling C, Newman LS. Chronic kidney disease of unknown cause in agricultural communities. $N$ Engl $J$ Med. 2019;380(19):1843-1852. doi:10.1056/NEJMra1813869

100. Polo VS, Garcia-Trabanino R, Rodriguez G, Madero M. Mesoamerican nephropathy $(\mathrm{MeN})$ : what we know so far. Int J Nephrol Renovasc Dis. 2020;13:261.

101. Di Iorio BR, Bellasi A, Raphael KL, et al. Treatment of metabolic acidosis with sodium bicarbonate delays progression of chronic kidney disease: the UBI Study. J Nephrol. 2019;32(6):989-1001. doi:10.1007/s40620-019-00656-5

102. Sánchez-Lozada LG, García-Arroyo FE, Gonzaga G, et al. Kidney injury from recurrent heat stress and rhabdomyolysis: protective role of allopurinol and sodium bicarbonate. Am J Nephrol. 2018;48 (5):339-348. doi:10.1159/000494663

103. Butler-Dawson J, Krisher L, Asensio C, et al. Risk factors for declines in kidney function in sugarcane workers in Guatemala. J Occup Environ Med. 2018;60(6):548. doi:10.1097/JOM.000 0000000001284

104. Aguilar-Ramirez D, Raña-Custodio A, Villa A, et al. Decreased kidney function and agricultural work: a cross-sectional study in middle-aged adults from Tierra Blanca, Mexico. Nephrol Dial Transplant. 2020. doi:10.1093/ndt/gfaa041 


\section{Publish your work in this journal}

The International Journal of Nephrology and Renovascular Disease is an international, peer-reviewed open-access journal focusing on the pathophysiology of the kidney and vascular supply. Epidemiology, screening, diagnosis, and treatment interventions are covered as well as basic science, biochemical and immunological studies. The manuscript management system is completely online and includes a very quick and fair peer-review system, which is all easy to use. Visit http://www.dovepress.com/testimonials.php to read real quotes from published authors.

Submit your manuscript here: https://www.dovepress.com/international-journal-of-nephrology-and-renovascular-disease-journal 